\title{
True hermaphroditism with seminoma: A case report
}

\author{
YULIN LAI ${ }^{1,2^{*}}$, JIANSEN XIE ${ }^{3,4^{*}}$, PEIKAI TIAN ${ }^{5},{\text { LIMING } \text { ZHONG }^{3} \text { and LIANGCHAO NI }}^{1}$ \\ ${ }^{1}$ Department of Urology, Peking University Shenzhen Hospital, Institute of Urology, Shenzhen PKU-HKUST Medical Center, \\ Shenzhen, Guangdong 518036; ${ }^{2}$ Graduate Institute, Guangzhou Medical University, Guangzhou, Guangdong 511436; \\ ${ }^{3}$ Department of Hepatobiliary Surgery, Peking University Shenzhen Hospital, Shenzhen, Guangdong 518036; \\ ${ }^{4}$ Graduate Institute, Shantou University Medical College, Shantou, Guangdong 515041; ${ }^{5}$ Department of \\ Hepatobiliary Surgery, Shenzhen University General Hospital, Shenzhen, Guangdong 518036, P.R. China
}

Received April 30, 2018; Accepted September 21, 2018

DOI: $10.3892 / \mathrm{mco} .2018 .1760$

\begin{abstract}
The aim of the present study was to discuss the diagnosis and treatment of a patient with true hermaphroditism complicated by seminoma. The patient was a 35 -year-old man who was admitted to the Peking University Shenzhen Hospital with a retractable mass in the left inguinal region for 20 years. A computed tomography examination revealed right cryptorchidism. The postoperative pathology suggested true hermaphroditism with a seminoma. The results of immunohistochemical examination were as follows: Sal-like protein $4^{+}$(partially weak); octamer-binding transcription factor $4^{+}$(partially weak); CD117+; cytokeratin ${ }^{+}$; CD30 ${ }^{-}, \alpha$-fetoprotein ${ }^{-}$, inhibin- $\alpha^{-}$.The karyotypewas 46,XY.Adult true hermaphroditism combined with seminoma is rare in clinical practice. Combined histopathological analysis, immunophenotype detection and karyotype analysis are of great value in the diagnosis and differential diagnosis. Early intervention and combined surgery with radiotherapy and chemotherapy can significantly improve the prognosis of such patients.
\end{abstract}

\section{Introduction}

True hermaphroditism refers to the simultaneous presence of two types of gonadal tissue (testicular and ovarian), regardless of the patient's karyotype (1). The degree of external genitalia varies between males and females. The etiology and pathogenesis of true

Correspondence to: Dr Liangchao Ni, Department of Urology, Peking University Shenzhen Hospital, Institute of Urology, Shenzhen PKU-HKUST Medical Center, 1120 Lianhua Road, Shenzhen, Guangdong 518036, P.R. China

E-mail:1ncord@163.com

Dr Liming Zhong, Department of Hepatobiliary Surgery, Peking University Shenzhen Hospital, 1120 Lianhua Road, Shenzhen, Guangdong 518036, P.R. China

E-mail: zlmbdszyy@163.com

*Contributed equally

Key words: true hermaphroditism, testicular neoplasms, seminomas hermaphroditism have not yet been fully elucidated. Seminoma is a low-grade tumor that originates from testicular primordial germ cells, and it is the most common tumor of the testes (2). However, cases of true hermaphroditism with seminoma are rare. In the present case, the clinical manifestations, histological morphology and immunophenotype of an adult patient with true hermaphroditism combined with seminoma treated in our hospital are analyzed, and the diagnosis and treatment are discussed along with a literature search.

\section{Case report}

The patient was a 35-year-old man who was diagnosed with a retractable mass in the left inguinal region for 20 years and was admitted to Peking University Shenzhen Hospital (Shenzhen, China) on September 7, 2017. The patient did not complain of any specific discomfort and his past medical history was unremarkable. There is no blood relationship between parents. The patient's mother denied receiving sex hormones and exposure to radioactive substances during pregnancy, and there was no related history in the family. The patient was married with one child, reported normal sexual function and had normal growth and development. On physical examination the pubic hair exhibited male distribution, the appearance of the external genitalia was male and of normal size, the urethral orifice was normal and there were no hypospadias; on palpation, the left testis was present and of normal size, but the right scrotum was empty. Following admission, blood tests, coagulation function tests, liver and renal function tests, and infectious disease were all normal. The $\beta$-human chorionic gonadotropin level was $<0.5 \mathrm{IU} / 1$ (normal range, 0-2.67 IU/1), the carbohydrate antigen (CA) 125 level was $8.5 \mathrm{U} / \mathrm{ml}$ (normal range, $0-35.0 \mathrm{U} / \mathrm{ml}$ ), the CA15-3 level was $4.7 \mathrm{U} / \mathrm{ml}$ (normal range, $0-31.3 \mathrm{U} / \mathrm{ml}$ ), the CA19-9 level was $<2.00 \mathrm{U} / \mathrm{ml}$ (normal range, 0-37.0 U/ml), the $\alpha$-fetoprotein (AFP) level was $2.6 \mathrm{ng} / \mathrm{ml}$ (normal range, $0-13.4 \mathrm{ng} / \mathrm{ml}$ ) and the carcinoembryonic antigen level was $1.1 \mathrm{ng} / \mathrm{ml}$ (normal range, 0-5.0 ng/ml). Color Doppler ultrasound in the inguinal region indicated that the right cryptorchidism was likely associated with liquefaction and calcification (Fig. 1). An enhanced pelvic computed tomography (CT) scan (Fig. 2) demonstrated that the right scrotum did not contain a testicle, and revealed a nodular shadow of abnormal density in the right iliac fossa. The boundary was clear and the size was 
$\sim 33.0 \times 18.0 \mathrm{~cm}$, with spotted and nodular calcifications in the periphery. No obvious enhancement, and cryptorchidism was considered as a possible diagnosis. Mixed scrotal density was observed on the left side, and the presence of a left inguinal hernia was considered. Therefore, the diagnosis on admission was: i) Left inguinal hernia and ii) right cryptorchidism. Laparoscopic total extraperitoneal inguinal hernia repair and laparoscopic cryptorchidectomy were successfully performed. After surgery, the patient was discharged without complications. The findings of the postoperative pathological examination of the right testicular specimen were consistent with development of a seminoma in an ovotestis (Fig. 3). The results of the immunohistochemical examination were as follows: Sal-like protein $4^{+}$(partially weak); octamer-binding transcription factor $4^{+}$(partially weak); CD117+; cytokeratin ${ }^{+} ; \mathrm{CD}^{+} 0^{-}, \alpha$-fetoprotein ${ }^{-}$, inhibin- $\alpha$.

\section{Discussion}

True hermaphroditism is a gonadal abnormality characterized by the simultaneous presence of testicular and ovarian tissue in the same patient. The incidence rate is $\sim 1 / 20,000$ (1). At present, the etiology and pathogenesis of this condition remain obscure, but sex chromosome abnormalities, abnormal gonadal development and related endocrine disorders and other factors during embryonic development may be implicated (2). Studies have shown that sexual differentiation and gonadal development require the involvement of sex-determining region $\mathrm{Y}$ (SRY), steroidogenesis factor-1, anti-Müllerian hormone gene, sex-determining region $\mathrm{Y}$ box protein 9, Wilms' tumor-1, dose-sensitive sex reversal-congenital adrenal dysplasia gene 1 and other genes involved in the development of hereditary disorders (3-5). Among those, the SRY gene is the best candidate as a testis-determining factor, and $\sim 66.7 \%$ of true hermaphroditism cases are found on genetic analysis to have SRY mutations (6). In addition, exogenous hormones, particularly pregnant women exposed to estrogen and progesterone during the early and middle pregnancy, may affect the normal differentiation of fetal gonads and increase the risk of sexual development abnormalities (7).

The testis and ovaries of patients with true hermaphroditism may be combined to form ovotestes, or they may exist separately. In true hermaphroditism patients, the presence of an ovotestis is the most common, followed by the presence of an ovary, whereas the presence of a testis is the least common (8). The karyotypes of patients with true hermaphroditism are mainly 46XX, 46XY, and 46XX/46XY, 46XY/45X and other chimeras (9). The karyotype analysis result for this patient was 46XY. Regarding genital development in patients with true hermaphroditism, studies have found that it is associated with ipsilateral gonads, and changes in the accessory renal tube determine genital development. If the patient's gonad is the testis, the accessory renal tubular inhibitory factor produced by the patient degenerates the accessory renal tube; if the gonad is the ovary, it does not produce the accessory renal tubular suppressor, and the accessory renal tube eventually develops into the uterus, fallopian tubes and vagina. The majority of the patients with true hermaphroditism exhibit a range of different external genitalia. Most patients exhibit clitoral enlargement or a small penis. Study data indicate that $\sim 2 / 3$ 's of true

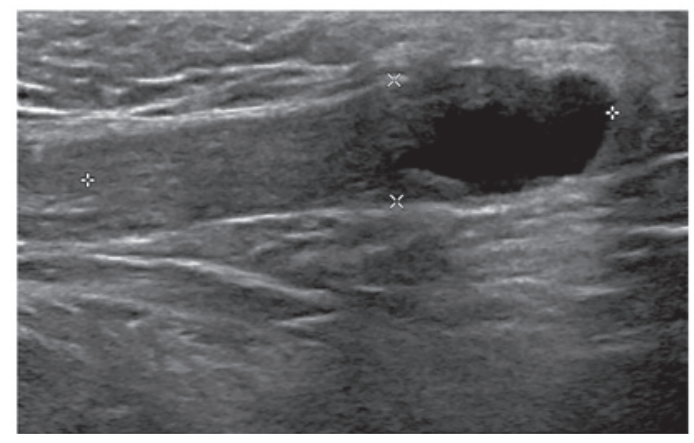

Figure 1. Ultrasound examination of the inguinal area revealed no testicular echo in the right scrotum, and a substantial mixed acoustic echo mass of $\sim 35 \times 16 \mathrm{~mm}$ in the right inguinal area. The nature of the mass was unknown, but cryptorchidism (with liquefaction and calcification) was considered.

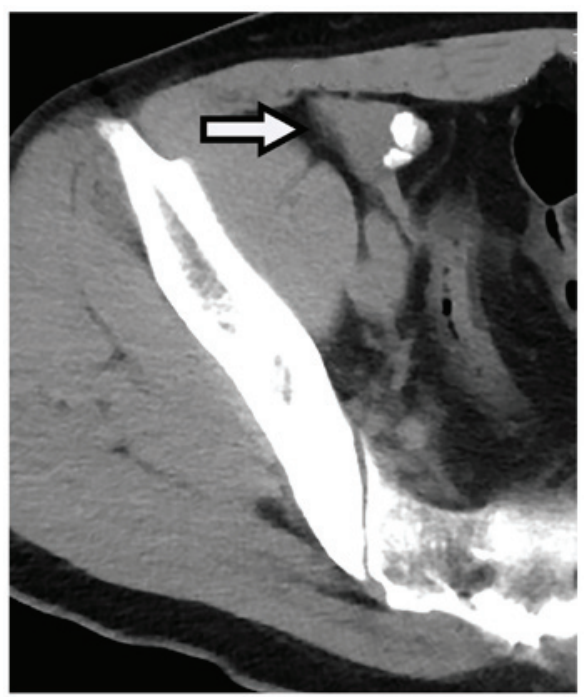

Figure 2. Pelvic computed tomography revealed absence of the testicle in the right scrotum, and a nodular abnormal density shadow in the right iliac fossa (arrow). The boundary was clear, and the size was $\sim 33.0 \times 18.0 \mathrm{~cm}$.

hermaphroditism patients live as men. If the patient's androgen secretion is insufficient during embryonic development and the scrotum and penis are not developed at birth, the patient often leads life as a woman (10). In the present case, the patient lived as a male, exhibited male secondary sexual characteristics, had no evident abnormalities in the external genitalia, and there was no mammary gland development. This may indicate that the patient's androgen secretion during the embryonic stage was sufficient to drive the development of the scrotum and penis. In terms of diagnosis, sex hormone testing, Doppler ultrasound, CT and magnetic resonance imaging, among other tests, play an important auxiliary role and help determine the status of hormone secretion and the structure of the gonads and internal genitalia. However, surgical exploration and histopathological examination confirm that the presence of both types of gonads in the body remains the gold standard for the diagnosis of true hermaphroditism (11). In the present case, pathological examination revealed ovarian tissue in a region of the testis. The karyotype was 46XY, and the diagnosis of true hermaphroditism was confirmed.

Seminomas originate from testicular primordial germ cells, are low-grade, and are the most common type of 


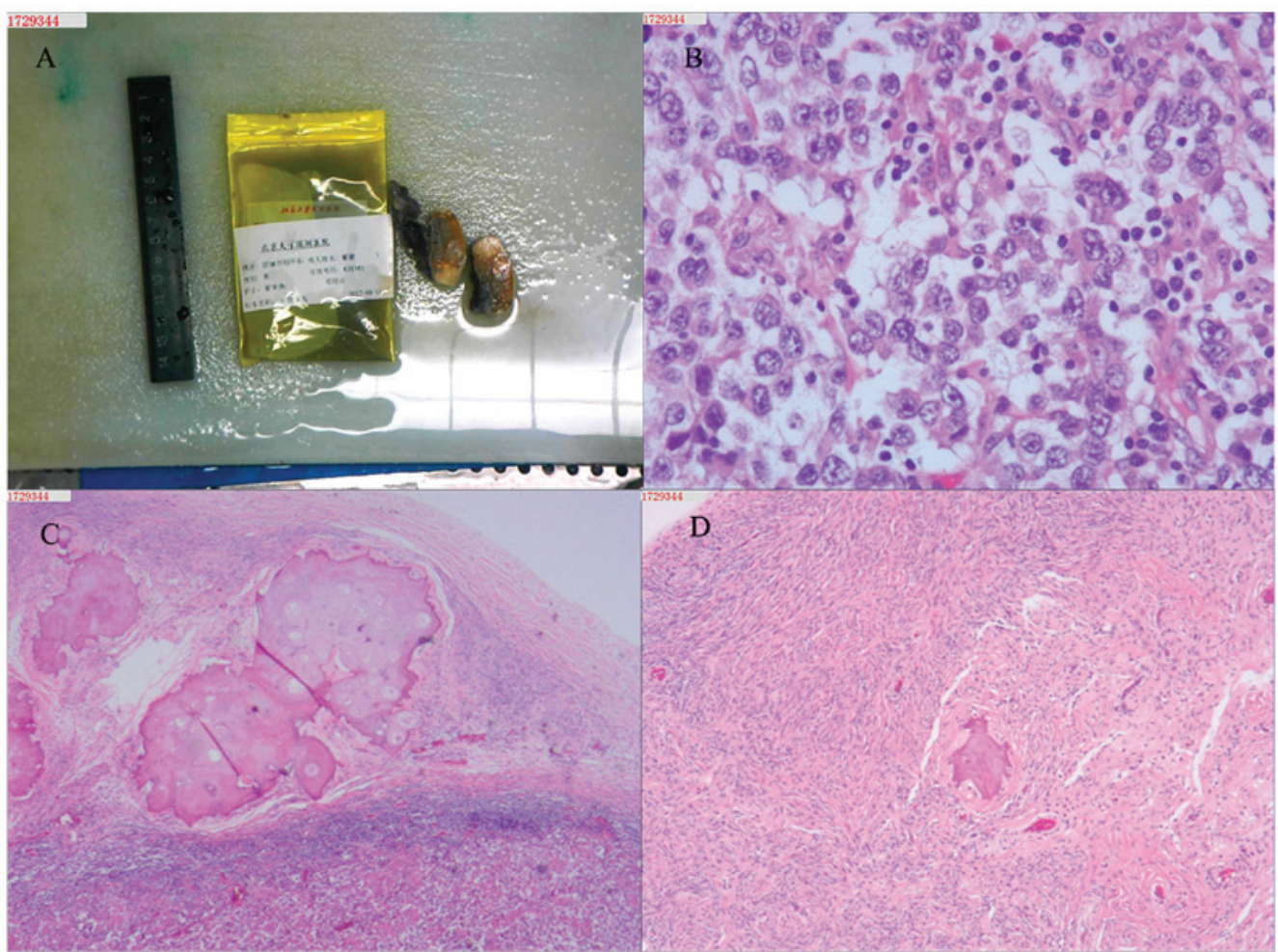

Figure 3. (A) Gross examination of removed testicular tissue, sized 4.0x2.5x1.2 cm. The cut surface was yellowish-brown and soft, and included a grey mass, slightly harder in texture. The size of the epididymis was $4.0 \times 1.5 \times 1.0 \mathrm{~cm}$. (B) In testicular tissue, spermatogenic cells in the seminiferous tubules were highly atrophic or absent, the basement membrane was significantly thickened, and hyalinization was observed, along with stromal cell proliferation. (C) Ovarian-like tissue was detected in an area of the testicular tissue. (D) In the testicular tissue, more irregularly shaped large cells were arranged in a nodular pattern, with scattered interstitial lymphocytes. Combined with immunohistochemistry, the findings were consistent with seminoma.

testicular tumor, accounting for $\sim 30-40 \%$ of all cases (12). Seminoma mostly occurs in middle-aged patients, is often unilateral, and slightly more common on the right. The disease is more likely to metastasize through the lymphatic pathway, and extensive hematogenous metastases may occur at the advanced stage, even to the skin $(13,14)$. In the diagnosis of this disease, pathology and immunohistochemistry are of important reference value. Placental alkaline phosphatase (PLAP) and CD117 are currently recognized and widely used as tumor markers for the diagnosis of seminoma $(15,16)$. However, PLAP positivity cannot exclude other germ cell tumors. CD117 is a type III transmembrane protein tyrosine kinase growth factor receptor, of which $>90 \%$ of testicular seminomas are positive, but embryogenic cancer is negative. Therefore, it is commonly used in the identification of spermatogonial tumor (16). Biermann et al (17) found that M2A and AP-2 $\gamma$ have higher diagnostic sensitivity. In addition, Ying et al (18) demonstrated that the positive expression rates of $\mathrm{M} 2 \mathrm{~A}$ and $\mathrm{AP}-2 \gamma$ in seminoma were 95 and $87.5 \%$, respectively, while the positive expression rates of PLAP and CD117 were 67.5 and $75 \%$, respectively. The expression of M2A and AP- $2 \gamma$ was significantly different from that of PLAP and CD117, suggesting that the positive expression of M2A and AP- $2 \gamma$ is valuable in the diagnosis of seminoma. In recent years, the discovery of new tumor markers, such as MAGEC2 and CAGCMTM2, have enabled early diagnosis of seminomas (19-21). The immunohistochemistry results in our patient revealed that CD117 was positive, whereas AFP and CD30 were negative. Combined with the clinical characteristics and histopathological examination, the diagnosis of seminoma was confirmed.

Seminoma in adult cryptorchidism combined with true hermaphroditism is rarely reported in clinical practice. The patient in the present case was a 35-year-old male with right cryptorchidism for over 30 years. Pathological examination revealed the presence of both types of gonads and the karyotype was $46 \mathrm{XY}$, which is a typical true hermaphroditism. Seminoma in cryptorchidism is significantly more common compared with normal testes (22) and it may be associated with the location of cryptorchidism, the high temperature in the abdominal cavity, endocrine disorders, local blood circulation disorders, gene mutations and other factors (23-25). In terms of treatment, patients with true hermaphroditism must be treated as men or women based on factors such as age, sex, gender, stability of the sex gonads, reproductive tract and external genitalia, and the consent of the parents/guardians. After weighing the abovementioned factors, surgical treatment and hormone replacement therapy are selectively used according to the circumstances; in cases of gonad-associated malignancies, the gonads should be immediately removed and regional lymph node dissection and postoperative radiotherapy and chemotherapy should be performed according to the tumor stage (26). The incidence of seminoma in patients with cryptorchidism was significantly higher compared with that in normal subjects. Early correct intervention is crucial for preventing malignant transformation of the undescended testis. Corrective surgery is recommended for children with cryptorchidism aged $<2$ years. However, if the patient is 
aged $\geq 2$ years, the undescended testicles should be surgically removed. If malignant change has occurred, the treatment of testicular neoplasms is carried out in accordance with the general principles of treatment of testicular tumors (27). Since seminoma originates from primordial germ cells, it is highly sensitive to radiotherapy and chemotherapy. Surgery combined with radiotherapy and chemotherapy can significantly improve the prognosis. The clinical stage of the tumor and the presence of hematogenous and/or lymphatic metastasis are the main factors affecting the prognosis of seminoma $(28,29)$.

\section{Acknowledgements}

Not applicable.

\section{Funding}

The present study was supported by the National Natural Science Foundation of China (grant no. 81101922), the Science and Technology Development Fund Project of Shenzhen (grant nos. JCYJ20150403091443329 and JCYJ20170307111334308), the fund of 'San-ming' Project of Medicine in Shenzhen and the fund of Guangdong Key Medical Subject.

\section{Availability of data and materials}

Not applicable.

\section{Authors' contributions}

LN and LZ conceived and designed the study. YL, PT and JX collected literature data and clinical information. YL and JX drafted and edited the manuscript. All the authors have read and approved the final version of the manuscript.

\section{Ethics approval and consent to participate}

The patient provided written informed consent preoperatively.

\section{Patient consent for publication}

The reported case has been approved by the patient for academic exchange only.

\section{Competing interests}

The authors declare that they have no competing interests.

\section{References}

1. Liang YF: The hermaphroditism of human. Biologic Teach 29: 51-52, 2004.

2. Jing $H$, Xinhua $T$ and Baosheng $Z: 46, X X$ male syndrome genetic diagnosis and clinical analysis. Chin J Androl 17: 68-72, 2011 (In Chinese).

3. Mendonca BB, Domenice S, Arnhold IJ and Costa EM: 46, XY disorders of sex development (DSD). Clin Endocrinol (Oxf) 70 173-187, 2009.

4. Yanqin $Y$ and Xiaoping L: Diagnosis and differentiation program of sexual development disorder. J Clin Pediatr 25: 965-970, 2007

5. Xiaoyu C and Shulan Z: Research progress of the correlation between Y-box protein 2 and gynecologic malignancy in sex determination area. Chin J Pract Gynecol Obst 31: 1048-1051, 2015.
6. Xia XY, Cui YX,Lu HY, Yang B, Wang GH,Pan LJ,Hou BS, Ge YF, Shao Y, Yao B and Huang YF: Clinical, molecular and cytogenetic studies on 4 patients with 46,XX (SRY positive) male syndrome. Zhonghua Nan Ke Xue 13: 1094-1097, 2007 (In Chinese).

7. Martin OV, Shialis T, Lester JN, Scrimshaw MD, Boobis AR and Voulvoulis N: Testicular dysgenesis syndrome and the estrogen hypothesis: A quantitative meta-analysis. Environ Health Perspect 116: 149-157, 2008.

8. Enhao G: Modern plastic surgery. Beijing, People's Military Medical Press, pp921-933, 2002.

9. Deng M, Zhao H, Che Z, Wang R, Qi H and Nie W: Report of 1 case of true hermaphroditism and literature review. Chin J Androl 26: 55-56, 2012 (In Chinese).

10. Zeyi C: Chinese obstetrics and gynecology. Beijing, People's Medical Publishing House, 2014.

11. Cui J, Dou JT, Yang GG, Gu WJ, Zang L, Jin N, Wang XL, Yang LJ, Lu ZH, Ba JM, et al: Diagnosis and management of ovotesticular disorders of sex development: A clinical study of 14 cases. Chin J Pract Int Med 4: 346-350, 2015.

12. Boujelbene N, Cosinschi A, Boujelbene N, Khanfir K, Bhagwati S, Herrmann E, Mirimanoff RO, Ozsahin M and Zouhair A: Pure semiuoma: A review and update. Radiat Oneol 6: 90, 2011.

13. Tickoo SK, Hutchinson B, Bacik J, Mazumdar M, Motzer RJ, Bajorin DF, Bosl GJ and Reuter VE: Testicular seminoma: A clinicopathologic and immunohistechemical study of 105 cases with special reference to seminomas with atypical features. Int J Surg Pathol 10: 23-32, 2002.

14. Tazi H, Badraoui M, Qasmi S and Hassam B: Metastatie pure testicular seminoma of the skin. Prog Urol 21: 76-78, 2011 (In French).

15. Yinghao Y: Immunohistochemical diagnosis and differential diagnosis of testicular tumors. Chin J Misdiagnosis: 543-546, 2006.

16. Liu DL, Lu YP, Shi HY, Zhu SX, Lü JW, Li WF and Rong X: Expression of CD117 in human testicular germ cell tumors and its diagnostic value for seminoma and nonseminoma. Zhonghua Nan Ke Xue 14: 38-41, 2008 (In Chinese).

17. Biermann K, Klingmüller D, Koch A, Pietsch T, Schorle H, Büttner R and Zhou H: Diagnostic value of markers M2A, OCT3/4, AP-2gamma, PLAP and c-KIT in the detection of extragonadal seminomas. Histopathology 49: 290-297, 2006.

18. Ying T, Yuanhua $\mathrm{C}$ and Anzhi W: Expression and significance of M2A,AP-2 $\gamma$, OCT3/4, PLAP and CD117 in seminoma. J Pract Med 27: 1338-1340, 2011

19. Bode PK, Barghorn A, Fritzsche FR, Riener MO, Kristiansen G, Knuth A and Moch H: MAGEC2 is a sensitive and novel marker for seminoma: A tissue microarray an analysis of 325 testicular germ cell tumors. Mod Pathol 24: 829-835, 2011.

20. Davis-Dao CA, Siegmund KD, Vandenberg DJ, Skinner EC, Coetzee GA, Thomas DC,Pike MC and Cortessis VK: Heteregenous effect of androgen receptor CAG tract length on testicular germ cell tumor risk: Shorter repeats associated with seminoma but not other histology types. Carcinogenesis 32: 1238-1243, 2011.

21. Zhenhua L, Tao X and Yunbei X: Tissue microarray technique was used to detect the expression of CMTM2 in human testicular tumor tissues. Chin J Male Sci 23: 3-6, 2011 (In Chinese).

22. Gang L, Bo Y and Yongsheng S: Clinical analysis of 15 cases of secondary malignant transformation of cryptorchidism. J Beihua Univ (Nat Sci) 13: 557-559, 2012 (In Chinese).

23. Bigot P, Droupy S, Houlgatte A, De Crevoisier R and Fléchon A: Stage I seminoms: Therapeutic strategy: Surveillance, radiotherapy, chemotherapy. A case-report. Prog Urol 21 (Suppl 2): S453-S457, 2011.

24. Yang Z and Daguang W: Pelvic tumor characteristics and diagnosis and treatment. Chin J Pract Surg 31: 533-535, 2011 (In Chinese).

25. Zhiyu W, Jian C, Lichang L, et al: Bilateral cryptorchidism complicated with unilateral malignant seminoma: A case report. Chin J Androl 16: 662-663, 2010 (In Chinese).

26. Yu L and Xin X: Report of a case of true glandular malignant glandular malignant transformation. Chin J Aesthetic Med 3: 326-327, 2004 (In Chinese).

27. Hua X, Liu SJ, Lu L, Li CX and Yu LN: Clinicopathological characterization of true hermaphroditism complicated with seminoma and review of the literature. Chin J Androl 18: 719-722, 2012 (In Chinese).

28. Eble JN, Sauter G, Epstein JI and Sesterhenn IA: World Health Organization Classification of Tumours. Pathology and genetics of tumours of Urinary system and male genital organs. Lyon, IARCP Press, pp260-261, 2004.

29. Qiao B and Wen Z: The diagnostic criteria and treatment plan of cryptorchidism in children. Pract J Pediatr 27: 1847-1848, 2012. 